\title{
Double whammy? Are the most at risk the least aware? A study of environmental justice and awareness of flood risk in England and Wales
}

\author{
J.L.Fielding \\ University of Surrey, UK
}

\section{DRAFT}

ABSTRACT: This paper explores the environmental inequalities of living in the flood plains of England and Wales and the differences in flood awareness of those 'at risk'. Large area differences are seen in both flood risk likelihood and also in flood awareness. Furthermore these differences are often class dependent. In all areas except the Midlands, the working classes are more likely to be resident in the flood plains and the greatest inequality is seen in the NE and in the Anglian region. It was found that flood awareness in some areas, especially the NE, was much lower than average and furthermore, these low perceptions of risk were disproportionately displayed by the most deprived. Wales was another region which shows low awareness but is high flood risk. But in Wales, it is the middle classes who exhibit the least awareness.

\section{INTRODUCTION}

Flood risk is an issue of increasing concern in the UK. In England and Wales alone, some five million people and two million properties are defined as being in areas that are at risk of flooding (Environment Agency 2005) ${ }^{1}$. The number of people at a high risk from flooding could rise from 1.5 million to 3.5 million between 2030 and 2100. (Foresight Future Flooding report, 2004) and the potential scale of social and economic disruption becomes all too clear. The problem is of considerable concern to the Environment Agency who, since the severe flood events of 1998, 2000 and more recently in 2007, has placed a high priority on the need to increase public awareness with regard to flood risk.

The issue of who is at risk and whether there are inequalities in the distribution of flood risk is also of concern here. This is the arena of environmental justice and social equality. Interest in environmental justice originated in the USA in the 1980's and was mainly concerned with the co-location of waste sites and heavy industries in areas predominantly populated by ethnic minorities. Environmental justice has been defined by the US Environmental Protection Agency as the fair treatment and meaningful involvement of all people regardless of colour, race, national origin or income with respect to the development, implementation, and enforcement of environmental laws and regulations (US Environmental Protection Agency EPA 1998 ). In the UK however, the issue of environmental justice is now high on the agenda of policy makers and funding agencies (EA, 2001; ESRC,2001).
However, these concerns of unequal risk to the population have now extended to all kinds of environmental risks, including natural risks, such as flood and earthquake risk (Blaikie et al. 1994; Buckle et al. 2000; Enarson and Fordham 2001; Wisner et al. 2003).

Recent research for the UK Environment Agency (Walker et al. 2003) found no disproportionate distribution of the population in the lower (more deprived) deciles residing within the fluvial flood plain of England, although there did seem to be a relationship between more deprived ward populations and flood hazard in tidal flood plains. Walker et al (2006) further extended this work using the more recent Environment Agency 2004 flood maps, deprivation deciles derived from the IMD2004 data aggregated to super output areas (SOAs) (population, approx 1,500), and the Ordnance Survey=s AddressPoint 7 to capture those addresses at risk within each SOA. Again though, it was acknowledged that a limitation of this method is that >all addresses within a SOA are still necessarily assumed to have the same deprivation characteristics' (Walker et al. 2006:52). Once again, they found that inequality existed within the tidal flood plains in all regions within England and Wales but no overall inequality within the fluvial flood plains although there was great regional variation in inequalities within the fluvial flood plains.

To explore different measures of inequality within the flood plains and to try to address the problem of aggregating deprivation profiles to large areas such as wards and the SOA, Fielding and Burningham (2005) employed a spatial method which redistributed population characteristics, derived from 
the 1991 Census data, as population grids using Surface Builder, a freely-available program. These spatially distributed, characterised, populations were then >captured $=$ and defined as >at risk $=$ if they resided within the extent of the Environment Agency indicative flood map. Their research found that overall, the lower social classes and the unemployed experienced a greater flood risk (Fielding \& Burningham 2005) but no distinction was made between tidal and fluvial risk. This research was then extended using the 2004 Environment Agency flood maps and the 2001 Census (Fielding, 2007) and a distinction was made between the fluvial and tidal flood risk. Fielding showed using surface population models and logistic regression analysis that there was a significant inequality existed between the middle and working classes, and also between the middle classes and the inactive (the unemployed and unclassifiable classes, not the retired), in risk factors associated with flood emergencies in all Environment Agency Regions of England and Wales except the Midlands region. That research demonstrated that overall, inequality is reproduced in both the fluvial and tidal flood plains, although that within the tidal flood plains is especially significant and more pronounced in some areas, especially, in the Eastern regions of England.

So it is clear that there are inequalities in the distribution of flood risk in the UK but whether those inequalities have arisen because those communities are disadvantaged or in spite of their disadvantage is a debate that continues. Talih and Fricker (2002) determined that there are two approaches to studying environmental justice. The first determines whether there is an association between distinguishing demographics and the location of environmentally undesirable sites and the second examines how such associations may have occurred. Therefore they maintain that the existence of environmental inequality does not necessarily imply that any overt discrimination has occurred because of their disadvantage but in spite of their disadvantage. In other words association is not enough to discern any positive discrimination, evidence of that would be the conclusion of a causal analysis. However, this is not to say that this association is not inequitable. Indeed, there are many studies which show that the poor, the disabled, the young, women, the very old etc. are less able to cope, physically, financially, psychologically in extreme situations such as during or following a flood (Fordham 1998; Fordham 1999; Tapsell et al. 2002; Cutter 2003; Wisner et al. 2003; Cutter et al. 2003; Cutter \& Emrich 2006).

Another framework for exploring these ideas is that of an emic and etic conceptualisation of vulner- ability or risk (see Spiers 2000, Fielding et al 2005b). These concepts, re-interpreted from linguistics and anthropology, refer to two complementary perspectives.

An etic viewpoint defines vulnerable individuals as those at greater risk based either on where they live (in vulnerable places, such as flood plains) or on demographic characteristics (vulnerable people). These characteristics are usually seen as those which increase social dependence; ie. old age, ill health, disability, and ethnicity (in terms of language barriers). Quantitative methods are nearly always used to identify vulnerable places (measuring the likelihood of an event occurring) and are also often used to identify vulnerable people. One negative consequence of this approach is that individuals may become stereotyped based on the defining functional deficit. Another problem is that such defined >vulnerable groups $=$ are not homogenous .

In contrast, an emic viewpoint seeks to identify vulnerability on the basis of meanings held by individuals arising from their lived experience and tends to be aligned with qualitative methodology. Emic vulnerability is founded on a person=s/family=s/community=s sense of their own resilience and ability to respond in the face of a flood. In terms of flood risk, emic vulnerability can only be determined by the person experiencing it. So, a person who may be defined as belonging to an at-risk group (etic vulnerability) may only feel vulnerable if they consider some threat to their self to exceed their capacity to adequately respond, despite 'rationally' acknowledging their possession of vulnerable characteristics. They need to recognise that they are at risk before they can effectively prepare.

\section{RISKY PLACES AND RISKY PEOPLE}

To explore these issues centrally depended upon the identification of risky places and risky people. Respondents were defined as those $>$ at risk $=$ from tidal or fluvial flooding but who may never have actually experienced a flood event. The $>$ at risk $=$ samples were identified by the use of flood plain maps. It may seem obvious that residents within the flood plains are most at risk from flooding and comprise the $>$ at risk= population but measuring the extent of the flood plains and quantifying the likelihood of floods is a contentious exercise exacerbated by many factors ranging from climate change to the involvement of the insurance industry.

The Environment Agency (EA) maps identified the >risky places $=$ but were also used to identify the $>$ at risk= population living within them. This 
$>$ at risk= population was then targeted by the EA >awareness campaigns $=$ designed to educate the vulnerable public about flood facts

A potential five million people and 2 million homes and businesses were targeted. However, the flood maps were an etic, outsider measure of those at risk, and recognition of their risk by those affected was clearly important for appropriate public action in preparation for any future disaster.

\section{PUBLIC AWARENESS OF RISK}

Quantitative secondary analysis of the $>$ at risk $=$ population based on a 2001 survey reported that 49 percent of residential respondents were not aware that their property was in a flood risk area (Fielding et al 2005a). This made apparent that the message was not getting through. Nearly half those defined as >at risk= were not aware of their risk. Thus, while the quantitative measurement of the extent of the flood plains had been used to identify the $>$ at risk= population, other quantitative analysis identified a differing perception of reality. The imposed, outsider view defining risky places was at odds with the lived experience of those defined $>$ at risk $=$.

Why were those who are vulnerable according to etic measures not aware of their risk? This was initially explored using the survey data relating other variables to >explain= variation in the dependant variable, awareness. However, the other variables chosen, generally those indicating, in line with the literature, a social or financial dependency, drew on etic, or outsider, analysis to explain lack of awareness. This did establish a clear social class gradient, with the lower social classes, the very young and the very old least aware of their flood risk (Fielding et al 2007). Further research by Burningham et al., showed that flood awareness varies between populations, with the disadvantaged often those who are least aware (Burningham et al, 2008). However, lack of awareness on it's own, measured quantitatively, does not necessarily reveal the complete picture. Green et al (2001) has shown that people's expectations of their flood risk is based on their past experience and this often leads them to underestimate the impact of rare and exceptional flood events. Burningham et al. (2008) concluded that people evaluate their risk based on past experience and their apparent lack of awareness may be accounted for by their local knowledge and their belief that 'it will never happen to me'. They also found that people may acknowledge their lack of awareness but either be unconcerned or in denial of their risk accounting for this by placing blame on their lack of trust in the providers of information. The invisibility of flood risk is also seen as a factor in people's response because you can't see it it doesn't exist. Another factor is that acknowledgement of flood risk is perhaps an acknowledgement of the devaluation of their home, a recognition that perhaps their home may be uninsurable or even unsaleable.

Depending on personal circumstances, recognition of vulnerability to flood risk according to the etic flood maps may either be accepted and acted upon, a situation where the emic and etic perspective coincide, or rejected where etic and emic viewpoints are at variance. In this later case, there are two possibilities. Firstly, the respondent is not actually at risk - due either to an error in the flood maps (the respondent lives on an isolated hill or recent flood defences have not been taken into account) or personal circumstance (the respondent lives above the ground floor). Secondly, the respondent is at risk (according to the map) but does not perceive this risk to be significant. As previously discussed, reasons for this are diverse. They may lack information about the risk; through past experience and local knowledge their perception of their ability to cope may exceed their perception of the risk; acknowledging the risk may have negative impacts (psychological and/or economic); and they may distrust the flood maps.

Thus previous research has shown that inequalities between classes exist in the distribution of flood risk in the fluvial and tidal flood plains in England and Wales and that in addition, there are class differences in flood awareness, this research explores the variation in risk inequality and the correspondence of inequalities in flood awareness

\section{METHODOLOGY}

To explore environmental inequality, risky areas were defined using the flood maps and risky populations were characterised using 2001 Census data as described in more detail below and in Fielding and Burningham (2005) and in Fielding (2007). Flood awareness was investigated using a secondary analysis of data collected in 2001 by the British Market Research Bureau (BMRB) for the Environment Agency (see Fielding et al,. (2005) for further details of methodology).

\subsection{Identification of risky areas}

Areas at risk were those defined by the Environment Agency as those within the zone 2 flood plains. 
Flood plain maps, based on annual risk, differentiate between those with little or no risk (zone 1: less than one in a thousand year chance of any flooding), those with low to medium risk (zone 2: more than 1 in a 1000 year risk of flooding from both rivers or the sea) and those living in high risk areas (zone 3: those with more than a 1 in a 100 year chance of river flooding and/or more than a one in 200 year chance of sea flooding). Zone 2 flood zones represent the extent of an extreme flood event. Note that those living within zone 2 will also include those living within zone 3 .

\subsection{Characteristics of 'at risk' populations}

Area statistics for social class were downloaded from the 2001 Census via CASWEB ${ }^{2}$ from Table CAS044, NS-SEC of Household Reference Persons (HRP) aged 16-74 in England and Wales. Data, with spatial referents, were then entered into SPSS for preliminary recoding of social class (NS-SEC) before entering (as csv format files) into Surface Builder $^{3}$ to create six separate social class grids:

- Higher and lower managerial \& professional

- Intermediate occupations

- Small employers and own account workers

- Lower supervisory and technical occupations

- Semi-routine and routine occupations

- Never worked and long-term unemployed/Unclassified.

Surface Builder, developed by David Martin (Martin \& Brackan 1999), imputes the distribution of larger area statistics (in this case, output areas) into $200 \mathrm{~m}$ grid squares based on the population centroids for each area (Martin 1989; Brackan \& Martin 1989). These surface population grids are then imported into Arc View for analysis. (see Fielding and Burningham (2005) and Fielding (2007) for a full description of this methodology).

For the purpose of comparison and a clearer analysis, these six class groupings were recoded into three groups: middle class; working class and never worked/inactive.

\section{RESULTS AND DISCUSSION}

An initial analysis of populations 'at risk' showed that the Thames region (14\%), followed by Anglian Region (13\%) had the highest proportion of their populations within the Zone 2 flood plains(Figure 1). The Midlands region was least at flood risk (7\%) The question as to whether these area risk differences have arisen due to any direct discrimination such as greater building on the flood plains - or whether these areas are just more heavily populated and therefore there is a greater likelihood of risk, is not being explored her and would be the subject of further research. The question of interest here was whether there were class inequalities within these EA regions?

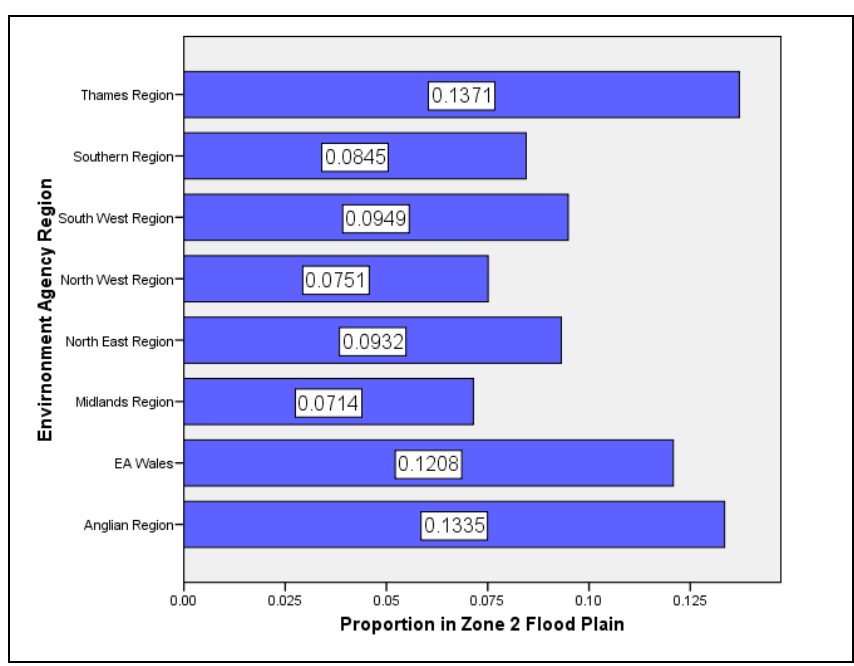

Figure 1. Proportion of households within the Zone 2 flood plains by Environment Agency Region

Previous research (Fielding, 2007) has shown that class inequalities exist in all EA areas except the Midlands region with regard to overall flood risk. The working classes are more likely to be resident in the flood plains than the middle classes (Figure 2).

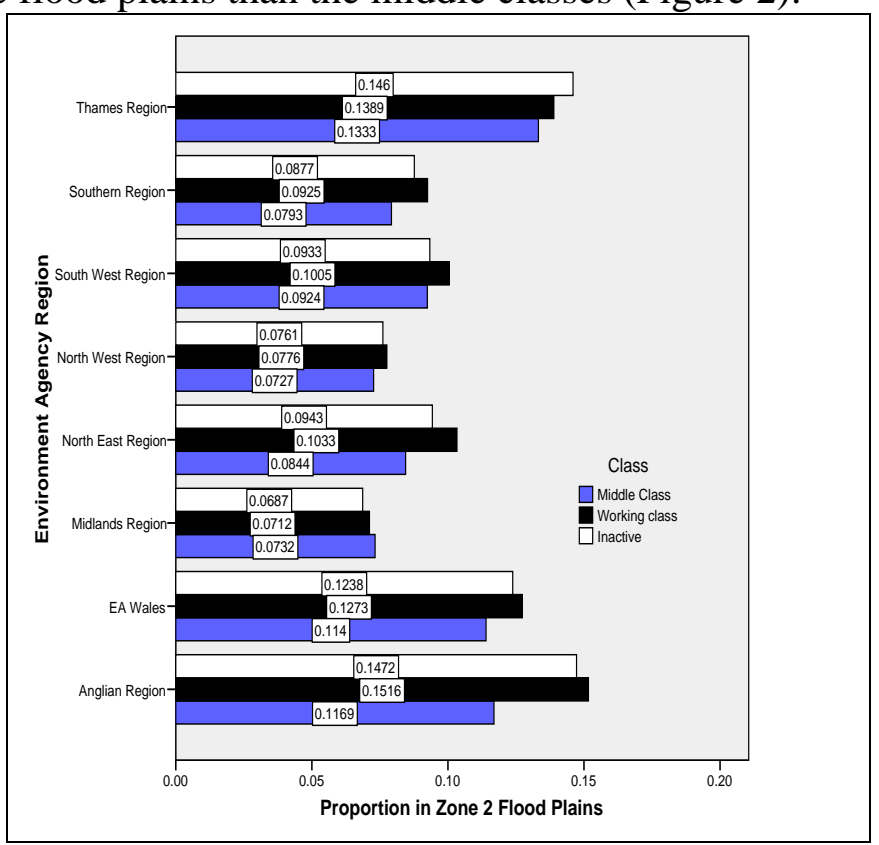

Figure 2 Proportion in Zone 2 flood plains by EA Region by class

Table 1 compares the odds ratios of being middle class vs. being either working class or inactive and being at flood risk. Odds ratios larger than 1.00 indicate greater likelihood of being at risk. Here we see that inequality is greatest in the Anglian and North Eastern Regions. The working classes in the Anglian 
and the NE regions are 35\% and 25\%, respectively, more likely to be resident in the zone 2 flood plains than the middles classes in those regions.

Table 1. Odds Ratios of being working class or inactive vs. middle class, and at flood risk

\begin{tabular}{llll}
\hline EA Region & $\begin{array}{l}\text { Middle } \\
\text { Class }\end{array}$ & Working Class & Inactive \\
\hline Anglian & 1.00 & 1.35 & 1.30 \\
EA Wales & 1.00 & 1.13 & 1.10 \\
Midlands & 1.00 & 0.97 & 0.93 \\
North East & 1.00 & 1.25 & 1.13 \\
North West & 1.00 & 1.07 & 1.05 \\
South West & 1.00 & 1.10 & 1.01 \\
Southern & 1.00 & 1.18 & 1.12 \\
Thames & 1.00 & 1.05 & 1.11 \\
\hline
\end{tabular}

These results are to be contrasted with an analysis obtained using the 'at risk' survey conducted for the EA in 2001 by BMRB (BMRB 2001). In this survey the following question was asked of all residents:

'Were you aware before now that your address is in an area which may be at risk of flooding?'

Figure 3 displays overall flood awareness in England \& Wales.

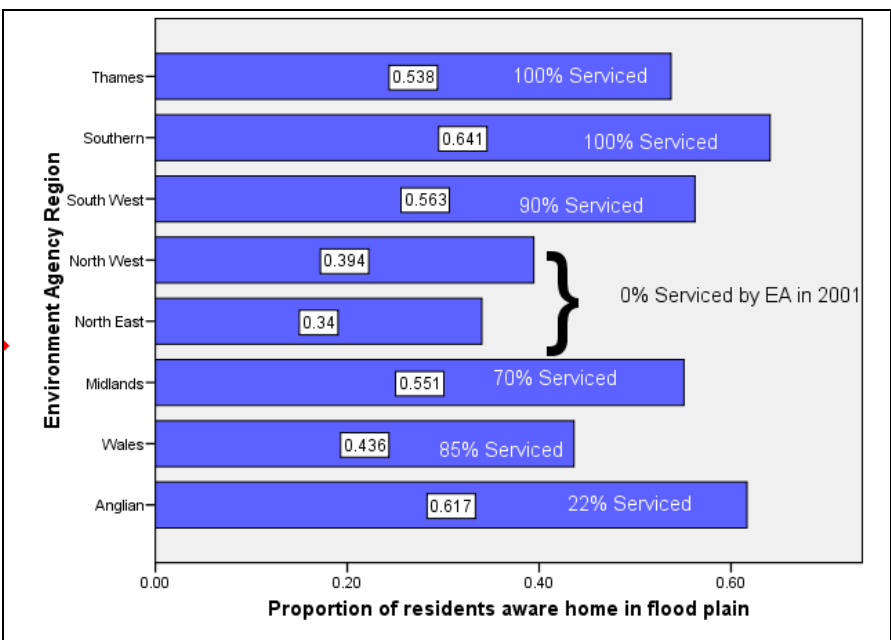

Figure 3. Proportion aware home in flood plain by EA region

Clearly, the NE and NW regions are least aware but those two regions are also not serviced by the EA in 2001. 'Serviced' areas are those properties within a Flood Warning Area which have been offered both a direct (automatic voice messaging, siren, loud hailer, flood warden, knocking on doors, pager, fax and letter) and indirect (Floodline, radio, TV, Teletext, Ceefax and internet) warning service. 'Non-serviced' areas are those properties within the floodplain which are not offered a direct flood warning service from the Environment Agency. The Agency is not able to offer a flood warning service in areas where they cannot use the necessary telemetry. However, these properties may receive general mailings from the Agency. Yet one of the most aware areas is that of East Anglia despite being only $22 \%$ of respondents being serviced. Thus it seems that EA servicing is not enough to explain differences in awareness.

Once again class inequalities were explored within region to find that despite differing levels of flood risk within regions, most regions show no significant class differences. The one exception was the North East. Here, the working classes and the inactive are significantly less likely to be aware of their risk (Figure 4) (Chi square $=10.6 ; \mathrm{p}<0.01$ ).

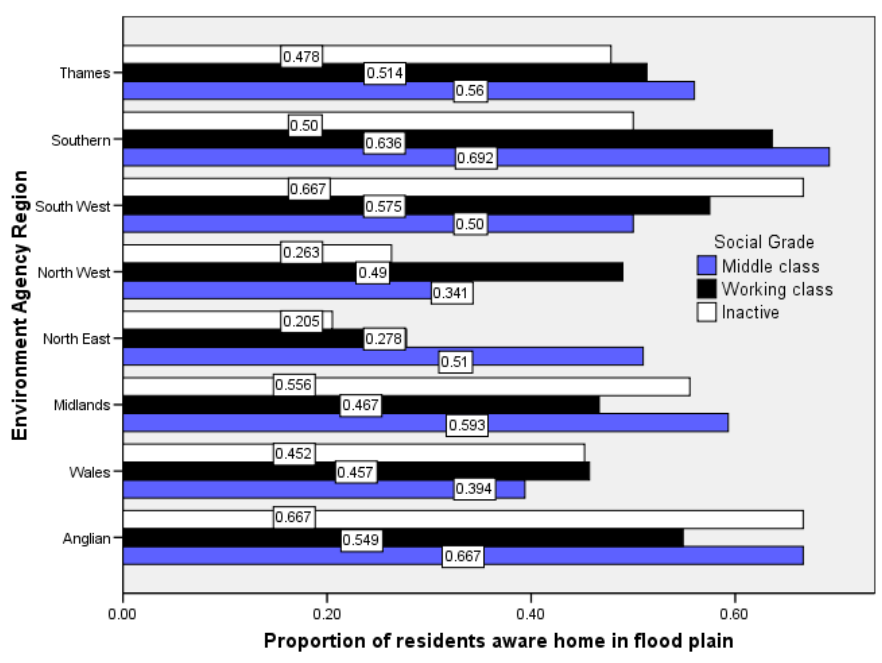

Figure 4. Proportion of Residents aware home in flood plain by EA region

These results are summarised in Table 2 which shows the odds ratios of being working class or inactive and being aware of flood risk vs. being middle class and aware of flood risk. In this table, odds ratios less than 1.00 indicate that respondents in those areas are less aware of their risk compared to the middle classes in the area.

Table 2 Odds ratios of being working class or inactive vs. middle class and being aware home in the flood plains

\begin{tabular}{lllll}
\hline EA Region & $\begin{array}{l}\text { Middle } \\
\text { Class }\end{array}$ & Working Class & $\begin{array}{l}\text { Inac- } \\
\text { tive }\end{array}$ & Sig. \\
\hline Anglian & 1.00 & 0.61 & 1.00 & $\mathrm{Ns}$ \\
EA Wales & 1.00 & 1.29 & 1.27 & $\mathrm{Ns}$ \\
Midlands & 1.00 & 0.60 & 0.86 & $\mathrm{Ns}$ \\
North East & 1.00 & 0.37 & 0.25 & $*$ \\
North West & 1.00 & 1.85 & 0.69 & $\mathrm{Ns}$ \\
South West & 1.00 & 1.35 & 2.00 & $\mathrm{Ns}$ \\
Southern & 1.00 & 0.78 & 0.44 & $\mathrm{Ns}$ \\
Thames & 1.00 & 0.83 & 0.72 & $\mathrm{Ns}$ \\
\hline
\end{tabular}

* Chi Sq significance <0.01; Ns-not significant

So the working classes in Wales, the NW and the SW are more aware than the middle classes $(29 \%$, $85 \%$ and $35 \%$ respectively more aware) of their risk, but these results are not significantly different from the perceptions of the middle classes. Conversely, in Anglia, the Midlands, Southern and Thames regions the working classes are less aware of their risk but once again this result is not significantly different to 
the perceptions of the middle classes. However, in the NE, the working class and the inactive are both significantly less likely to be aware of their risk than the middle classes - 63\% (1.00-0.37) less likely and $75 \%(1.00-0.25)$ less likely respectively.

These two sets of results were then explored together to establish which areas were high risk/high awareness; high risk/low awareness; low risk/high awareness and low risk/low awareness for all classes and for each class group separately. In each of the following figures the $\mathrm{X}$ and $\mathrm{Y}$ reference lines have been drawn in at the group average (ie. All/ middle class/working class/inactive) for risk likelihood and for awareness.

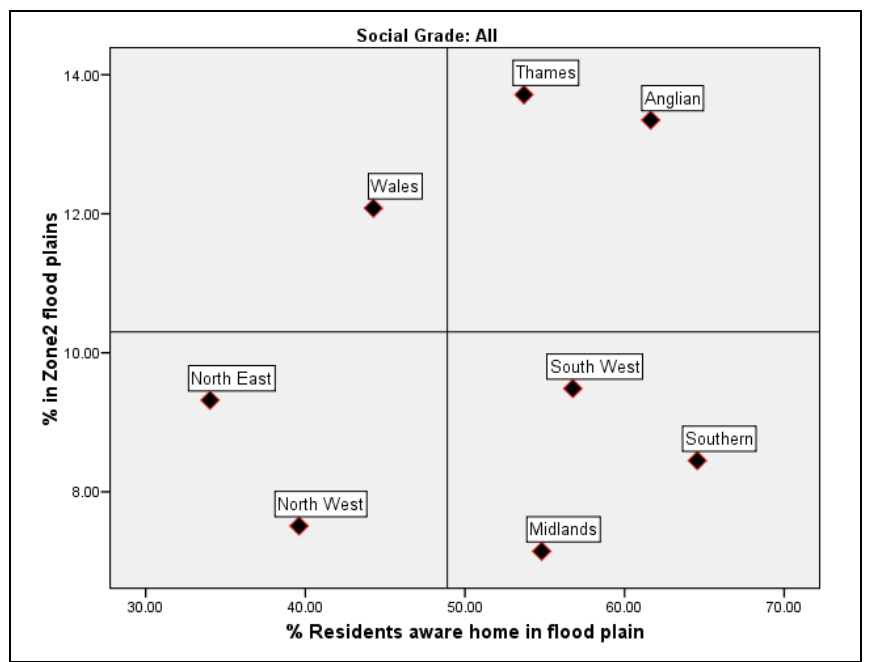

Figure 5. Overall flood risk and flood awareness

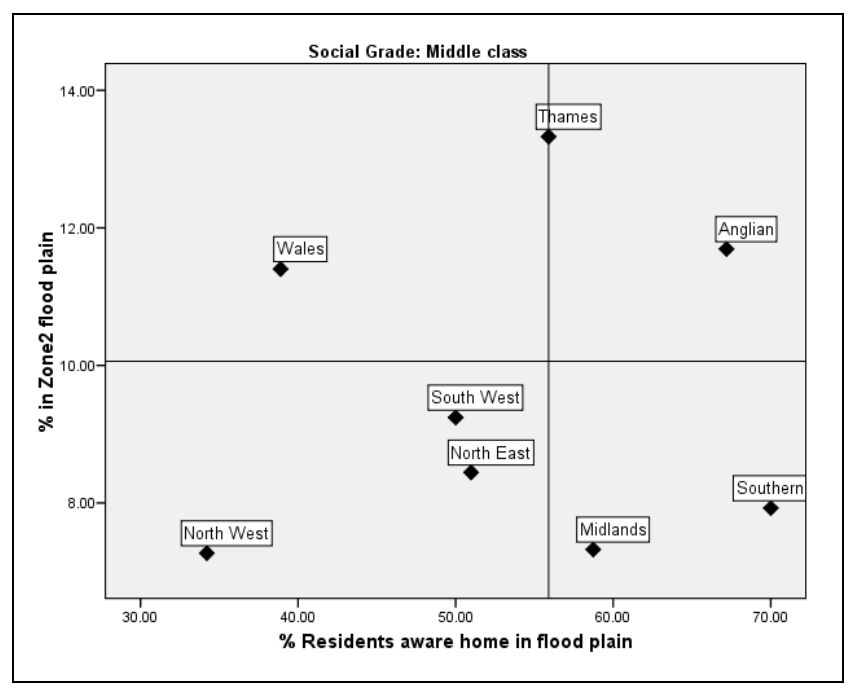

Figure 6. Flood risk and flood awareness among the middle classes

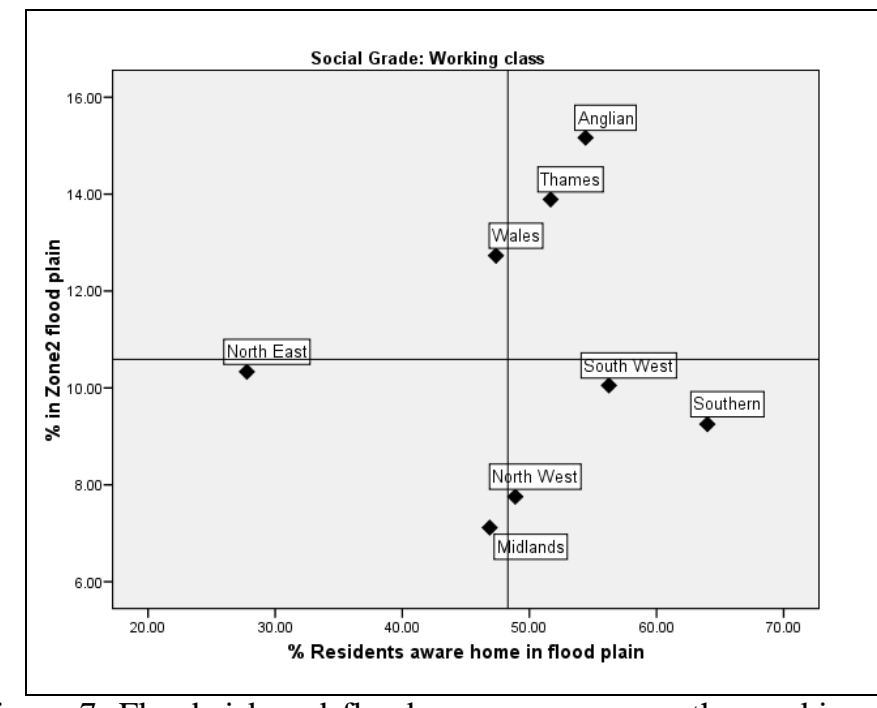

Figure 7. Flood risk and flood awareness among the working classes

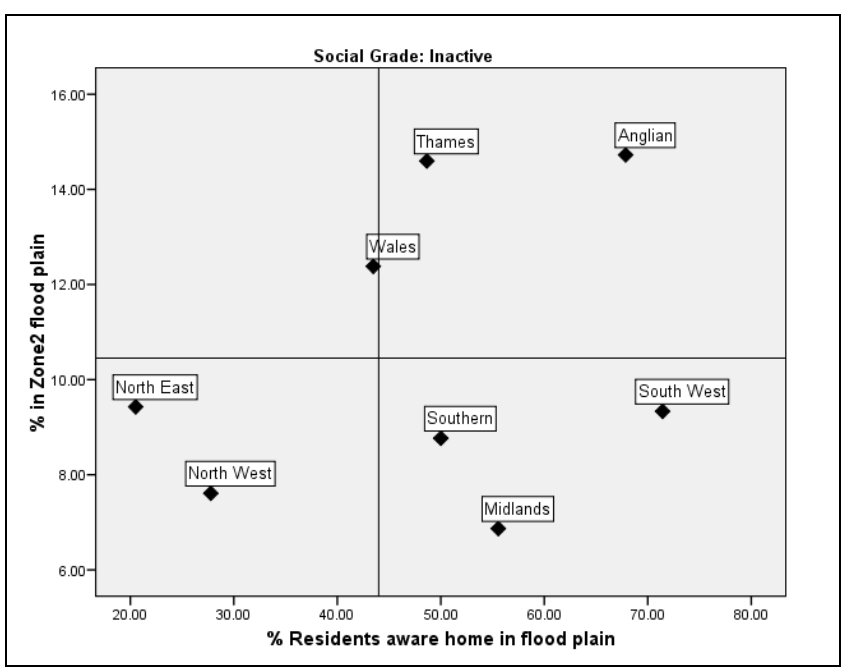

Figure 8. Flood risk and flood awareness among the inactive.

Thus overall, the NE and the NW are low risk but also low awareness, while Wales is high risk and low awareness (Figure 5). Looking at the middle classes (Figure 6), the regional differences seen overall are replicated although the middle classes in the SW display below average awareness. However, among the working classes, the NE stands out as a region of borderline/high risk and low awareness (Figure 7) and among the inactive (Figure 8), the NE and NW once again stand out as areas of low awareness although low risk.

\section{DISCUSSION}

Clearly there are large area differences in both flood risk likelihood and also flood awareness. Furthermore these differences are often class dependent. In all areas except the Midlands, the working classes are more likely to be resident in the flood plains and the greatest inequality is seen in the $\mathrm{NE}$ and in the Anglian region. However, these inequalities may not have arisen through any positive discrimination and 
their development should be an area for further research. Yet, despite uncertainly regarding the origins of these inequalities, there is much research to show that these inequalities are inequitable. Such research has shown (Fordham 1998;Fordham 1999; Tapsell et al. 2002; Cutter 2003; Wisner et al. 2003; Cutter et al. 2003;Cutter \& Emrich 2006) that it is often the most deprived who are lest able to cope in a flood event and these results should be of concern to policy makers and flood emergency managers developing flood warning policy. However, these are all measures of objective, etic risk defined by the flood maps. It is equally important to explore and understand the perception of those people living within those areas, the emic, subjective risk. This research has explored that subjective risk quantitatively using a secondary analysis of survey data. It was found that flood awareness in some areas, especially the $\mathrm{NE}$, was much lower than average and furthermore, these low perceptions of risk were disproportionately displayed by the most deprived. It should also be noted that Wales is another region which shows low awareness but is high flood risk. But in Wales, it is the middle classes who exhibit the least awareness.

Thus, area differences in awareness are complex and there is great regional variation, not only in awareness but also flood risk. However, while all areas (except the Midlands) show a disproportionate increase in flood risk falling on the working and inactive classes, there are some areas where this is especially pronounced such as the NE. And in addition, in the NE, perhaps because of this inequality, this area is significantly less likely to be aware of the flood risk and indeed experience a "double whammy”.

\section{REFERENCES}

Blaikie, P., Cannon,T., Davis,I. \& Wisner, B. 1994. At risk, natural hazards, peoples vulnerability and disaster. London \& New York: Routledge.

BMRB (British Market Research Bureau). 2001. 'At Risk' 2001 Survey for the Environment Agency.

Brackan, I. \& Martin, D. 1989. The generation of spatial population distributions from census centroid data. Environment and Planning A, 21: 537-543.

Buckle, P., Marsh, G., \& Smale, S. 2000. New approaches to assessing vulnerability and resilience. Australian Emergency Management Journal 15: 8-15.

Burningham, K., Fielding, J., Thrush, D. 2008. 'It'll never happen to me': understanding public awareness of local flood risk. Disasters 32 (2): 216-238.

Burningham, K., Fielding, J., Thrush, D., \& Gray, K. 2005. Flood Warning for Vulnerable Groups Report for the Environment Agency, Science Summary SC990007/ss. Bristol:Environment Agency.

Cutter, S. L. 1993. Living with risk: the geography of technological hazards. Routledge: New York.
Cutter, S. L. 2003. The Vulnerability of Science and the Science of Vulnerability. Annals of the Association of American Geographers 93(1): 1-12.

Cutter, S. L., Boruff, B. J., \& Shirley, W. L. 2003. Social Vulnerability to Environmental Hazards. Source Social Science Quarterly 84(2): 242-261.

Cutter, S. L. \& Emrich, C. T. 2006. Moral Hazard, Social Catastrophe: The Changing Face of Vulnerability along the Hurricane Coasts. The Annals of the American Academy of Political and Social Science 604(1): 102-112.

Enarson, E. \& Fordham, M. 2001. Lines that divide, ties that bind: race,class and gender in women's flood recovery in the US and UK. Australian Journal of Emergency Management 15(4): 43-52.

EA (Environment Agency) 2001. Achieving Environmental Equality. Environment Agency AGM Debate $5^{\text {th }}$ September 2000. Bristol: Environment Agency.

EPA (US Environmental Protection Agency ) 1998. Guidance for incorporating environmental justice in EPA's NEPA compliance analysis. Washington DC: U.S Environmental Protection Agency.

ESRC. 2001. Environmental Justice. Rights and means to a healthy environment for all. ESRC Global Environmental Change Programme Special Briefing No.7. University of Sussex.

Fielding, J. 2007. Environmental Injustice or Just the Lie of the Land: an Investigation of the Socio-Economic Class of Those at Risk from Flooding in England and Wales. Sociological Research Online 12(4). http://www.socresonline.org.uk/12/4/4.html

Fielding, J. \& Burningham, K. 2005. Environmental inequality and flood hazard. Local Environment 10(4): 379-395.

Fielding, J. Gray, K.Burningham \& Thrush, D. 2005. Flood warning for vulnerable groups: secondary analysis of flood data. R\&D Report W5C-018/2. Bristol: Environment Agency.

Fielding, J., Burningham, K., Thrush, D. \& Catt, R. 2007. Public Response to Flood Warning R\&D Report SC02011: Bristol: Environment Agency.

Foresight Future Flooding Report. 2004.

http://www.environment-agency.gov.uk/subjects/flood/763964/ [Accessed April 27, 2008].

Fordham, M. 1998. Making Women Visible in Disasters: Problematising the Private Domain. Disasters 22(2): 126-143.

Fordham, M. 1999. The Intersection of Gender and Social Class in Disaster: Balancing Resilience and Vulnerability. International Journal of Mass Emergencies and Disasters. 17(1): 15-37.

Green, C.H., Tunstall, S.M. \& Fordham, M.H. 1991. The Risks from Flooding: Which Risks and Whose Perception? Disasters 15(3): 227-236.

Martin, D. 1989. Mapping population data from zone centroid locations. Transactions of the Institute of British Geographers NS 14: 90-97.

Martin, D. \& Brackan, I. 1999. CCS605:1981 and 1991 Population Surface Models: a Guide. University of Manchester: Census Dissemination Unit.

Spiers, J. 2000. New perspectives on vulnerability using emic and etic approaches. Journal of Advanced Nursing 31 (3):715-721.

Talih, M. \& Fricker, R. D. 2002. Effects of neighbourhood demographic shifts on findings of environmental injustice: a New York City case-study. Journal of the Royal Statistical Society: Series A (Statistics in Society) 165(2): 375-397.

Tapsell, S. M., Penning-Rowsell, E. C., Tunstall, S. M., \& Wilson, T. L. 2002. Vulnerability to flooding: health and social dimensions. Philosphical transactions - Royal Society of London Series A Mathematical and Physical Sciences. 360(1796): 1511-1525. 
Walker, G., Burningham, K., Fielding, J., Smith, G., Thrush, D., \& Fay, H. 2006. Addressing Environmental Inequalities: Flood Risk. Science Report SC020061/SR1. Bristol: Environment Agency.

Walker, G., Fairburn, J., Smith, G., \& Mitchell, G. 2003. Environmental Quality and Social Deprivation. R\&D Technical Report E2-067/1/TR. Bristol: Environment Agency.

Walker, G., Fairburn, J., \& Bickerstaff, K. 2000. Ethnicity and risk; the characteristics of populations in census wards containing major accident hazard sites in England and Wales. University of Staffordshire, Department of Geography Occasional Paper, 15.

Wisner, B., Blaikie, P., Cannon, T., \& Davis, I. 2003. At risk: natural hazards, people's vulnerability and disasters. 2nd edn. London \& New York: Routledge.

${ }^{1}$ http://www.environment-

agency.gov.uk/subjects/flood/?lang=_e [accessed

November 23, 2012]

2 . http://census.ac.uk/casweb/ [accessed

November 23, 2012]

http://www2.geog.soton.ac.uk/users/martindj/daveho me/software.htm

[accessed November 23, 2012] 